\title{
PREDICTORS OF PATIENTS' EXPERIENCES AND SATISFACTION WITH NURSING CARE IN MEDICAL-SURGICAL WARDS ${ }^{1}$
}

\author{
Gisele Hespanhol Dorigan², Henrique Ceretta Oliveira³, Edinêis de Brito Guirardello ${ }^{4}$
}

\footnotetext{
${ }^{1}$ Paper taken from the thesis entitled - Cross-cultural adaptation and validation of the Newcastle Satisfaction with Nursing Scales to Brazilian culture, presented to the Programa de Pós-Graduação em Enfermagem at the Universidade Estadual de Campinas (UNICAMP), in 2011.

${ }^{2}$ Doctoral student, Programa de Pós-Graduação em Enfermagem, Faculdade de Enfermagem, UNICAMP. Campinas, São Paulo, Brazil. E-mail: ghdorigan@gmail.com

${ }^{3}$ M.Sc. in Collective Health. Statistician at Faculdade de Enfermagem, UNICAMP. Campinas, São Paulo, Brazil. E-mail: hceretta@ fcm.unicamp.br

${ }^{4}$ Ph.D. in Nursing. Associate Professor, Faculdade de Enfermagem, UNICAMP. Campinas, São Paulo, Brazil. E-mail: guirar@ fcm.unicamp.br
}

\begin{abstract}
This study aimed to identify predictors of experiences and patient satisfaction with nursing care and compare the psychometric properties of the Brazilian version and the original version of the Newcastle Satisfaction with Nursing Scales. This is a cross-sectional study with 351 patients in medical-surgical units of a teaching hospital. The multiple linear regression method was used for data analysis. Satisfaction with nursing care in general was the predictor for experiences $(\mathrm{p}<0.0001)$ and satisfaction $(\mathrm{p}<0.0001)$. Other predictors of satisfaction with nursing care were age $(p=0.027)$, education level $(p=0.024)$ and satisfaction with hospitalization $(\mathrm{p}=0.021)$. We conclude that the Brazilian version of the instrument demonstrated satisfactory reliability and validity. In addition, it is easier to use and less expensive.
\end{abstract}

DESCRIPTORS: Patient satisfaction. Nursing care. Quality of health care. Health evaluation.

\section{FATORES PREDITORES DAS EXPERIÊNCIAS E DA SATISFAÇÃO DO PACIENTE EM UNIDADES MÉDICO-CIRÚRGICAS}

RESUMO: Objetivou-se identificar os fatores preditores das experiências e satisfação dos pacientes com o cuidado de enfermagem e comparar as propriedades psicométricas da versão brasileira e a versão original do Newcastle Satisfaction with Nursing Scales. Tratase de um estudo transversal com 351 pacientes em unidades médico-cirúrgicas de um hospital de ensino. Para a análise de dados foi utilizado o método de regressão linear múltipla. A satisfação com o cuidado de enfermagem em geral foi o fator preditor tanto para as experiências $(p<0,0001)$ como para a satisfação com a internação $(p<0,0001)$. Outros preditores da satisfação com a assistência foram a idade $(p=0,027)$, o nível de escolaridade $(p=0,024)$ e a satisfação com a internação $(p=0,021)$. Conclui-se que a versão brasileira do instrumento demonstrou confiabilidade e validade satisfatória, além de ser mais fácil de utilizar e de menor custo.

DESCRITORES: Satisfação do paciente. Cuidados de enfermagem. Qualidade da assistência à saúde. Avaliação em saúde.

\section{FACTORES PREDICTORES DE LA EXPERIENCIA Y LA SATISFACCIÓN DE LOS PACIENTES EN LAS UNIDADES MÉDICO-QUIRÚRGICAS}

RESUMEN: Este estudio tuvo como objetivo identificar los factores predictivos de la experiencia y la satisfacción del paciente con la atención de enfermería y comparar las propiedades psicometricas de la versión brasileña y la versión original del Newcastle Satisfaction with Nursing Scales. Se trata de un estudio transversal con 351 pacientes en unidades médico-quirúrgicas de un hospital universitario. Para el análisis de los dados se utilizó el método de regresión lineal múltiple. La satisfacción con la atención de enfermería en general fue el predictor de las experiencias $(p<0.0001)$ y la satisfacción con el internamiento $(p<0,0001)$. Otros predictores de la satisfacción con la atención fueron la edad ( $\mathrm{p}=0,027)$, el nivel de educación $(\mathrm{p}=0,024)$ y la satisfacción con la hospitalización $(\mathrm{p}=0,021)$. Llegamos a la conclusión de que la versión brasileña del instrumento demostró confiabilidad y validez satisfactorios, así como ser fácil de usar y menos costoso.

DESCRIPTORES: Satisfacción del paciente. Atención de enfermería. Calidad de la atención de salud. Evaluación en salud. 


\section{INTRODUCTION}

The assessment of health care quality has incorporated the patients' perspective and this subjective assessment is translated in the measuring of patients' satisfaction with the health service. ${ }^{1}$ It is considered an important indicator of care quality and a recent study proposes its use to assess the population's access to health. ${ }^{1-3}$

Although studies appoint the inconsistency in the definition of the patient satisfaction construct with nursing care, ${ }^{2,4}$ the most widely accepted definition in the literature considers it as the level of congruence between the patient's expectations and subjective perceptions of the care received. ${ }^{5}$

To assess the patient's satisfaction with nursing care, two specific tools are available in Brazil: the Patient Satisfaction Instrument (PSI) and the Newcastle Satisfaction with Nursing Scales (NSNS) - Brazilian version. ${ }^{6-7}$ The PSI has been used recently to assess puerperal women's satisfaction at a postpartum unit of a teaching hospital in the interior of the State of São Paulo, ${ }^{8}$ besides being used to measure the satisfaction of patients hospitalized at medical-surgical wards. ${ }^{6}$

The objectives of the NSNS, besides measuring the patients' satisfaction with nursing care, is to assess the patient's experiences during hospitalization and includes the following scales: the patient's Experiences with nursing care and the patient's Satisfaction with nursing care, which can be assessed independently.

Two questions are not included in the NSNS scales and have been used in different studies to assess whether they reflect the internal consistency of the tool, 9-12 as follows: "How would you rate the nursing care you have received on this unit? (Think about only the nursing care, not the atmosphere, food, cleanliness, noise etc.)" and "Overall, how would you rate your stay on this unit? (Think about everything about this unit: nursing care, atmosphere, food, cleanliness, noise etc.)".

The measuring of patients' satisfaction with nursing care can permit care management based on the subjects' needs and some studies demonstrate that individual care delivery results in a higher level of patient satisfaction. ${ }^{13}$ There is evidence that patient satisfaction with nursing care strongly influences the hospitalization experience and, therefore, determines the level of satisfaction with hospitalization in general, which includes not only nursing care as aspects of the unit structure and other support services for care delivery. ${ }^{1,14}$

Although most studies highlight that the patients are satisfied with nursing care, ${ }^{7,10}$ in view of a scenario of growing work demands, high competitiveness and the need for monitoring as a requirement for health institutions' accreditation processes, it is considered relevant to get to know what factors are of influence in the patients' experiences during hospitalization. In addition, the patient's perception of nursing care is appointed as the main predictor of patient satisfaction with nursing care, besides cooperation between physicians and nurses. ${ }^{15}$

Another more recent study, which assessed the relation between the patient satisfaction construct and the variables nursing effort and performance and the climate in the work environment, identified that task performance was an important predictor of patient satisfaction. The authors suggest the development of other studies to validate these findings that the positive perception of the organizational climate results in better nursing performance and can enhance the patients' satisfaction. ${ }^{16}$

It is highlighted that these authors did not use any specific tool to assess the patients' satisfaction with nursing care, but assessed using four items aimed at: assessing the satisfaction with nursing care, the patient's capacity to recommend the institution to a friend or relative, the patient's desire to return to the institution if he needed to and, finally, whether his needs were satisfied by the institution's services. ${ }^{16}$

No studies were found in the Brazilian literature aimed at assessing the predictors of the patients' experiences and satisfaction with nursing care. Therefore, the objectives in this study were to identify the predictors of patients' experiences and satisfaction with nursing care, besides comparing the translated and adapted versions of the NSNS for the Brazilian culture, which maintains the same items as the original version and the Brazilian version of the NSNS (B-NSNS). ${ }^{7-17}$

The difference between the two versions is that the first resulted from the translation and adaptation to the Brazilian culture, ${ }^{7}$ containing all items of the original version of the tool, ${ }^{11}$ while the Brazilian version of the NSNS contains less items and resulted from the validation process of the tool using the robust confirmatory factor analysis 
method, using the statistical method of Structural Equations Modeling. ${ }^{17}$

Motivated by the following guiding question, this study was developed: when compared to the translated and adapted version of the NSNS, is the Brazilian version of the NSNS, which contains less items (reduced through confirmatory factor analysis), reliable and valid to measure the experiences and satisfaction of adult patients hospitalized at medical-surgical units? What variables are significant to determine the positive experiences and satisfaction of adult patients hospitalized at medical-surgical units?

Considering that the validation process can never be watertight, the objectives in this study were to assess the predictors of the experiences and satisfaction of patients with nursing care and to assess the internal consistency of both versions of the NSNS. ${ }^{7}$

\section{METHODS}

A cross-sectional study was undertaken, whose database originated in the translation and cultural adaptation and validation studies of the NSNS for the Brazilian culture. ${ }^{7-17}$ The study received approval from the institution's Research Ethics Committee (Protocol n. 809/2009).

The sample consisted of patients who complied with the inclusion criteria, such as: a) age 18 years or older; b) identification of hospital discharge and/or expected hospital discharge, or transfer to another hospitalization unit; c) length of hospitalization equal to or longer than 24 hours; and d) conditions to answer and understand the data collection instrument.

To collect the data, the version of the NSNS adapted to the Brazilian culture was used, as well as a sociodemographic form. ${ }^{7}$

The data were analyzed using the statistical software Statistical Analysis System (SAS) version 9.2. Tests of adherence to the normal distribution were applied for the continuing variables, using the Kolmogorov-Smirnov test. For the comparisons involving the categorical variables related to the scores of the Experience and Satisfaction scales of the patient with nursing care, Mann-Whitney and Kruskal-Wallis' non-parametric tests were applied. The correlations between the scores and the quantitative variables were assessed using the Spearman correlation coefficient.

For the multiple linear regression analysis, the scores on the scales of Experience and Sat- isfaction with nursing care were considered as dependent variables, and the remaining variable under study as the independent variables of the models (age, sex, level of education, monthly family income, length of hospitalization, previous hospitalization at the unit, assessment of nursing care in general and assessment of hospitalization in general). The estimates of the regression coefficients were obtained, as well as their respective standard errors, confidence intervals and p-value, as well as the explained variance or explanation coefficient $\left(R^{2}\right)$ for each of the adjusted models.

For the two questions that assess the patient's satisfaction with nursing care in general and with the hospitalization, used in this study as independent variables of the multiple linear regression model, a seven-point Likert-type response scale is used (ranges from "dreadful" to "excellent").

To assess the reliability of the scales, Cronbach's alpha coefficient was used, considering values of 0.7 or higher as appropriate. ${ }^{18}$ For all statistical analyses, a significance level of $5 \%$ was used, that is, $\mathrm{a}=0.05$.

\section{RESULTS}

In total, 351 patients participated in the study, who complied with the inclusion criteria. The participants' mean age was 49.43 years $(\mathrm{SD}=15.55)$. The majority was male $(51.9 \%)$, with a mean education level of 6.7 full years $(S D=4.26)$ and a mean family income of 2.74 minimum wages $(\mathrm{SD}=1.71)$. It is highlighted that, during the data collection period, one minimum wage corresponded to R $\$ 510.00$.

On a scale from zero to 100 , the resulting mean score was $90.5(\mathrm{SD}=7.8)$ for the Experience scale and $84.7(\mathrm{SD}=5.0)$ for the Satisfaction scale with nursing care scale. The results of the multiple linear regression analysis for the scale of the patient's Experience and Satisfaction with nursing care, comparing the versions of the NSNS, are displayed in Table 1.

For the domain Experiences with nursing care, for both versions of the NSNS, the significant factor was the assessment of the patient's satisfaction with nursing care in general $(p<0.0001)$. For the translated and adapted version of the NSNS, the variable monthly family income demonstrated significance $(p=0.027)$. The $\mathrm{R}^{2}$ coefficient for the models amounted to $19.18 \%$ and $26.13 \%$, respectively, for the B-NSNS and for the translated and adapted version of the tool. 
Table 1 - Predictors of patients' Experiences and Satisfaction with nursing care for the versions of the Newcastle Satisfaction with Nursing Scales. Campinas-SP, $2011(n=351)$

\begin{tabular}{|c|c|c|c|c|c|c|}
\hline Dependent variable & Independent variable & $\beta^{*}$ & $\mathbf{S E}^{\dagger}$ & p-valor $\ddagger$ & $\mathbf{R}^{2 \S}$ & $\alpha \|$ \\
\hline Experiences (B-NSNS) & Satisfaction with nursing care in general & 4.75 & 0.83 & $<0.0001$ & 19.18 & 0.85 \\
\hline \multirow[t]{2}{*}{ Experiences (NSNS) } & Satisfaction with nursing care in general & 4.11 & 0.57 & $<0.0001$ & 26.13 & 0.90 \\
\hline & Age & 0.13 & 0.06 & 0.03 & \multirow{4}{*}{31.62} & \multirow{4}{*}{0.97} \\
\hline \multirow{4}{*}{ Satisfaction (B-NSNS) } & Education level & 0.51 & 0.22 & 0.02 & & \\
\hline & Satisfaction with nursing care in general & 7.35 & 1.03 & $<0.0001$ & & \\
\hline & Satisfaction with hospitalization in general & 2.09 & 0.90 & 0.02 & & \\
\hline & Age & 0.13 & 0.06 & 0.02 & \multirow{4}{*}{32.20} & \multirow{4}{*}{0.97} \\
\hline \multirow{3}{*}{ Satisfaction (NSNS) } & Education level & 0.50 & 0.22 & 0.03 & & \\
\hline & Satisfaction with nursing care in general & 7.33 & 1.02 & $<0.0001$ & & \\
\hline & Satisfaction with hospitalization in general & 2.08 & 0.89 & 0.02 & & \\
\hline
\end{tabular}

${ }^{*}$ Regression coefficient; ${ }^{\dagger}$ Standard error; ${ }^{\ddagger} \mathrm{p}$-value; ${ }^{\S}$ Explained variance; । Cronbach's alpha.

As regards the domain Satisfaction with nursing care, for the two versions of the NSNS, the significant factors were age $(\mathrm{p}=0.027 ; \mathrm{p}=0.019$, respectively), level of education ( $\mathrm{p}=0.024 ; \mathrm{p}=0.026)$, assessment of patient satisfaction with nursing care in general $(\mathrm{p}<0.0001 ; \mathrm{p}<0.0001)$ and $\mathrm{pa}-$ tient satisfaction with hospitalization in general $(\mathrm{p}=0.021 ; \mathrm{p}=0.019)$.

The $\mathrm{R}^{2}$ coefficient for the models amounted to $31.62 \%$ for the version that contained fewer items (B-NSNS) and $32.20 \%$ for the translated and adapted version.

For the B-NSNS, Cronbach's alpha coefficients corresponded to 0.85 for the scale of the patient's Experiences with nursing care and 0.97 for the scale of the patient's satisfaction with nursing care. The version of the NSNS equivalent to the original version showed Cronbach's alpha coefficients for the scales of Experiences and Satisfaction corresponding to 0.90 and 0.97 , respectively.

\section{DISCUSSION}

The results of this study demonstrated that, in general, the patients expressed high levels of satisfaction and positive experiences with nursing care during hospitalization. This finding supports earlier studies that also report high levels of patient satisfaction with nursing care. . $^{10,12,19}$

In a literature search, international studies were found with proposals similar to the present study, which used the NSNS as a specific tool to assess the experiences and satisfaction of hospitalized patients with nursing care. ${ }^{10,20-21}$ When comparing the independent variables in the present study's multiple linear regression model, among those studies, the most similar one shares five independent variables with what was analyzed (age, sex, length of hospitalization, income and level of education). ${ }^{10}$

The remaining authors only considered the construct patient's experiences with nursing care as the dependent variable for the model,$^{20}$ or the patient's satisfaction with nursing care.$^{21}$ In this study, the patient's experiences and satisfaction jointly were considered as the dependent variables. In addition, among the independent variables in these two studies, only four are common to the variables assessed in this study (sex, age, education level and length of hospitalization). The remainder are not included in the multiple linear regression model, like for example: the type of unit, length of the nurse's response to the call, information given to the family members and friends, etc.

The variable patient satisfaction with nursing care in general demonstrated to be a predictor for the construct patient's experience with nursing care as well as for patient satisfaction with nursing care.

For the construct patient satisfaction with nursing care, other predictors were: patient satisfaction with hospitalization in general, age and education level. In line with these findings, the level of education showed to be a significant variable, indicating that, the lower the education level, the higher the level of patient satisfaction with nursing care. ${ }^{10,21}$ In addition, the patient's satisfaction with nursing care is appointed as the main predictor of the hospitalization experience. ${ }^{15}$

The age variable resulted in one of the predictors of patient satisfaction for this study, in line with the findings of a recent study that used the Polish version of the NSNS, in which age was one 
of the predictors that influenced both the experiences and satisfaction of the hospitalized patients. ${ }^{9}$

It could also be identified that there exists a relation between the patient's satisfaction with nursing care and the patient's satisfaction with the hospitalization in general $(\beta=2.09 ; p=0.02)$, in line with the findings of other studies on the theme. ${ }^{1,14-15}$

As regards the predictors of the patient's experiences with nursing care, for this study, only the patient's satisfaction with nursing care in general, which includes the patient's assessment of all experiences involving nursing care, was the predictor. This finding differs from other studies on the theme, in which the length of hospitalization was the predictor of positive experiences for example, that is, the longer the hospitalization, the higher the score for the score in question. ${ }^{10}$ In the same study, the authors verified that the variables included in the model (age, level of education, sex, monthly family income, length of hospitalization, previous hospitalization at the unit, assessment of nursing care in general and assessment of hospitalization in general) explained up to $3.7 \%$ of the Experience construct $\left(\mathrm{R}^{2}=3.7 \%\right)$ and $7.9 \%$ of the construct patient Satisfaction with nursing care $\left(\mathrm{R}^{2}=7.9 \%\right) .{ }^{10}$

For this study, the explained variance coefficients $\left(R^{2}\right)$ in the models were higher than in the literature. ${ }^{10}$ The independent variables included in the model using the B-NSNS explained up to $19.18 \%$ of the Experience construct and $31.62 \%$ of the Satisfaction construct. A preliminary study, ${ }^{20}$ which assessed the predictors for the construct patient's experiences with nursing care only, showed a coefficient of $0.54 \%$ after adjusting the model. In the same study, besides the variables age $(\beta=-0.20$; $\mathrm{p}<0.001)$ and $\operatorname{sex}(\beta=-0.14 ; \mathrm{p}<0.001)$, the variables: speed of the nurses' response to the patient's call $(\beta=0.27 ; p<0.001)$; appropriate length of time spent on care $(\beta=0.23 ; p<0.001)$; appropriate amount of information $(\beta=0.19 ; p<0.001)$; help to relatives and friends $(\beta=0.18 ; p<0.001)$ and awareness of the patients' needs $(\beta=0.17 ; p<0.001)$ were also appointed as predictors of the patient's positive experiences. ${ }^{20}$

It is important to highlight that, in view of the robustness of the analyses, no great variation was observed between the models when using the translated and adapted version of the NSNS and the version of the B-NSNS). As regards the reliability, both models presented Cronbach's alpha coefficients higher than 0.80 , and were therefore considered satisfactory. ${ }^{18}$
As regards the reliability, a small drop was identified in the Cronbach's alpha coefficient for the scale patient's Experiences with nursing care in the Brazilian version of the NSNS, as more items were removed from this scale during the validation phase. ${ }^{17}$ These results can support the hypothesis that the Brazilian version of the NSNS (B-NSNS) is valid and reliable and that the use of this new version in care practice is easier and cheaper due to the shorter time and less material spent.

\section{CONCLUSIONS}

The predictors for the satisfaction of patients hospitalized at medical-surgical units were age, level of education, patient satisfaction with nursing care in general and satisfaction with the hospitalization in general. The only predictor for the patient's experiences was the patient's satisfaction with nursing care in general, which includes the assessment of the environment, food, cleaning and noise during the hospitalization period. The results of this study demonstrated that the Brazilian version of the NSNS (B-NSNS) showed coefficients of reliability to be applied at medical-surgical units.

It is highlighted that this is the first study in the Brazilian literature in which the predictors of the patient's experiences and satisfaction with nursing care were assessed. Among the limitations, the non-probabilistic convenience sample is evidenced, coming from a teaching hospital in the interior of the State of São Paulo. Therefore, the Brazilian version (B-NSNS) should be applied in probabilistic samples from different units and with different patient profiles to assess its psychometric behavior.

\section{REFERENCES}

1. Otani K, Waterman B, Faulkner KM, Burroughs TE, Dunagan WC. Patient satisfaction: focusing on "excellent". J Healthc Manag. 2009 Mar-Apr; 54(2):93-103.

2. Milutinovic D, Simin D, Brkic N, Brkic S. The patient satisfaction with nursing care quality: the psycometric study of the Serbian version of PSNCQ questionnaire. Scand J Caring Sci. 2012 Sep; 26(3):598-606.

3. Mpinga EK, Chastonay P. Satisfaction of patients: a right to health indicator? Health Policy. 2011 May; 100(2-3):144-50.

4. Wagner D, Bear M. Patient satisfaction with nursing care: a concept analysis within a nursing framework. J Adv Nurs. 2009 Mar; 65(3):692-701. 
5. Risser NL. Development of an instrument to measure patient satisfaction with nurses and nursing care in primary care settings. Nurs Res. 1975 Jan-Feb; 24(1):45-51.

6. Oliveira AML, Guirardello EB. Satisfação do paciente com os cuidados de enfermagem: comparação entre dois hospitais. Rev Esc Enferm USP. 2006 Mar; 40(1):71-7.

7. Dorigan GH, Guirardello EB. Tradução e adaptação cultural do Newcastle Satisfaction with Nursing Scales para a cultura brasileira. Rev Esc Enferm USP. 2013 Jun; 47(3):561-7.

8. Odinino NG, Guirardello EB. Satisfação da puérpera com os cuidados de enfermagem recebidos em um alojamento conjunto. Texto Contexto Enferm. 2010 Out-Dez; 19(4):682-90.

9. Gutysz-Wojnicka A, Dyk D, Cudak E, Ozga D. Measuring patient satisfaction with the Polish version of the Newcastle Satisfaction with Nursing Scale. Scan J Caring Sci. 2012 Jun; 27(2):311-8.

10. Findik UY, Unsar S, Sut N. Patient satisfaction with nursing care and its relationship with patient characteristics. Nurs Health Sci. 2010 Jun; 12(2):1629.

11. Thomas LH, McColl E, Priest J, Bond S, Boys RJ. Newcastle Satisfaction with Nursing Scales: an instrument for quality assessments of nursing care. Qual Health Care. 1996 Jun; 5(2):67-72.

12. Peterson WE, Charles C, DiCenso A, Sword W. The Newcastle Satisfaction with Nursing Scales: a valid measure of maternal satisfaction with inpatient postpartum nursing care. J Adv Nurs. 2005 Dec; 52(6):672-81.
13. Suhonen R, Papastavrou E, Efstathiou G, Tsangari H, Jarosova D, Leino-Kilpi H, et al. Patient satisfaction as an outcome of individualised nursing care. Scan J Caring Sci. 2012 Jun; 26(2):372-80.

14. Oflaz F, Vural H. The evaluation of nurses and nursing activities through the perceptions of inpatients. Int Nurs Rev. 2010 Jun; 57(2):232-9.

15. Larrabee JH, Ostrow CL, Withrow ML, Janney MA, Hobbs GR Jr, Burant C. Predictors of patient satisfaction with impatient hospital nursing care. Res Nur Health. 2004 Aug; 27(4):254-68.

16. Greenslade JH, Jimmieson NL. Organizational factors impacting on patient satisfaction: a crosssectional examination of service climate and linkages to nurses' effort and performance. Int J Nurs Stud. 2011 Dec; 48(12):1188-98.

17. Dorigan GH, Guirardello EB, Silva D, McColl E. Validation of the Brazilian version of the Newcastle Satisfaction with Nursing Scales: a partial least squares path modeling approach. J Nurs Meas. 2014; 22(3):451-60.

18. Hair JF, Anderson RE, Tathan RL, Black WC. Análise multivariada de dados. $6^{\mathrm{a}}$ ed. Porto Alegre (RS): Bookman; 2009.

19. Dorigan GH, Guirardello EB. Satisfação do paciente em uma unidade de gastroenterologia. Acta Paul Enferm. 2010 Jun-Jul; 23(4):500-5.

20. Ahmad MM, Alasad JA. Predictors of patient's experiences of nursing care in medical-surgical wards. Int J Nurs Pract. 2004 Oct; 10(5):235-41.

21. Alasad JA, Ahmad MM. Patients' satisfaction with nursing care in Jordan. Int J Health Care Qual Assur. 2003; 16(6):279-85. 